\title{
La tramitación y gestión de los expedientes de captación de aguas subterráneas en España durante el período 1800-1927. El ejemplo de la isla de Gran Canaria
}

\section{The Processing and Management of the Underground Water Collection Records in Spain During the Period 1800-1927: The Example of the Island of Gran Canaria}

\author{
Ángel García García \\ Gobierno de Canarias \\ Consejería de Educación, Universidades, Cultura y Deportes \\ http:/ / orcid.org/0000-0003-0593-5924 \\ angelgargar@gmail.com \\ Recibido: 07/09/2020; Revisado: 09/11/2020; Aceptado: 20/11/2020
}

\begin{abstract}
Resumen
Este artículo pretende realizar un estudio del marco jurídico, administrativo e institucional a cuyo cargo estuvo la tramitación de los expedientes de concesión para las captaciones de aguas subterráneas en el periodo 1800-1927, desde una perspectiva nacional e insular.
\end{abstract}

Palabras clave: Tramitación, expediente, agua, España, Gran Canaria.

\begin{abstract}
This article analyses the legal, administrative and institutional framework within which concession files for groundwater catchments were processed during the period of 1800-1927, both from a national and insular perspective.
\end{abstract}

Key words: Processing, File, Water, Spain, Gran Canaria. 


\section{INTRODUCCIÓN}

Este trabajo tiene como objeto el estudio de la normativa y de los procedimientos seguidos en la tramitación de los expedientes de aguas subterráneas y su aplicación en la isla de Gran Canaria. La normativa para regular los alumbramientos fue variada y necesitó de la promulgación de leyes, decretos, órdenes, circulares, etc. Este marco legal se elaboró sin una previa planificación hidráulica y sin la necesaria dotación de recursos técnicos-administrativos que permitiera el asesoramiento y facilitara los trámites a los peticionarios. Aunque se dictó con el propósito de solucionar los distintos problemas, conflictos y protestas que se producían entre particulares, sociedades y heredades en torno a la captación de aguas, no se obtuvieron los resultados previstos pues los litigios no hicieron más que aumentar.

La aplicación de esta normativa en Gran Canaria pone al descubierto que el Estado no tuvo en cuenta sus especificidades geofísicas al tiempo que, autorizaba captaciones que incumplían las normas establecidas y permitía graves irregularidades en los expedientes tramitados en la isla, lo que provocó innumerables conflictos. A la actuación del Estado hay que unir, aunque de forma muy general, las competencias y funciones desempeñadas por los gobernadores y los alcaldes en todo este proceso.

En aras de una mejor claridad expositiva, el trabajo se ha estructurado en tres apartados: el marco legislativo, el institucional-administrativo y el caso de Gran Canaria (ASCANIO y LEÓN, 1926), finalizando con unas breves conclusiones.

\section{EL MARCO LEGISLATIVO}

En este apartado se pretende hacer un repaso cronológico de la legislación española contemporánea que se ocupa de la captación de aguas subterráneas. En la etapa contemporánea española la regulación de las aguas subterráneas se inicia con el Decreto de 19 de mayo de 1816, ${ }^{1}$ la Real Orden de 31 de octubre de 1819 (GAY, 1921: 21) y la Ley de Minas de 1825. Esta última, en su artículo n ${ }^{\circ} 10$, establecía que las aguas de las minas y manantiales pertenecían a los sus dueños y a los vecinos de los pueblos, cuando comenzó a legislarse sobre las aguas subterráneas. ${ }^{2}$ A partir de entonces surge un importante compendio normativo sobre esta materia, entre los que se citan el Decreto de 4 de agosto de $1833,{ }^{3}$ estableciendo reglas para las concesiones en los ríos navegables y, para los que no fuesen de propiedad particular con posterioridad al 5 de abril de 1834, se dictó una Real Orden sobre el respeto que se debía tener a los aprovechamientos antiguos, ubicados en terrenos

1 Los distintos pontífices ceden a perpetuidad al emperador Carlos v y a los sucesivos reyes, los beneficios del diezmo para sangrar los ríos en los diferentes reinos y los barrancos en las Islas Canarias con el objeto de aumentar el riego con destino a la agricultura. En la realización de estas obras se implica a las tropas españolas, para no distraer la atención del trabajador del campo. La Gaceta de Madrid, $\mathrm{n}^{\circ}$ 64, de 21 de mayo de 1816, pp. 530-531.

2 La Gaceta de Madrid, de 7 de julio de 1825.

3 Ibidem. 
más bajos de aquellos a quienes se otorgaban concesiones (ABELLA 1877:19).

La Real Orden de 19 de noviembre de 1835 fue el primer paso para la reforma de esta legislación y de la reivindicación por la Nación de todas las aguas de los ríos. En ella se exime a los habitantes de Cataluña, Valencia y Mallorca de varios derechos que pagaban al Real Patrimonio y se les deja en libre facultad para construir molinos de harina, hacer calas y zanjas para buscar aguas subterráneas, sin otra sujeción que las reglas del derecho común (GAY, 1921: 25).

Entre los años 1834-1835, el estado fracasó en su intento por conocer la situación de las aguas en cada uno de los municipios, dada la resistencia y negativa de los alcaldes a remitir información o hacerlo de manera incompleta cuando no, como sucedió en el caso del municipio de Telde, al considerar que tal asunto era competencia de los alcaldes de aguas. A partir de entonces, el Estado tendrá una posición más favorable a la privatización de las captaciones de aguas (PÉREZ, 1990: 429-461) y de toda la infraestructura hidráulica (acequias, presas, etc.).

La ausencia de un modelo de desarrollo hidráulico (MACAU,1957) y de un manual normativo diáfano por la inacción del Estado, suscitan una importante conflictividad social entre particulares e instituciones que tuvieron como escenario las calles y los juzgados (Millares, 2008; SuÁrez, 1988; SuÁreZ y Trujillo, 2006: 77-165). Los grandes beneficiados de esta situación fueron los potentados, que disponían de los recursos económicos necesarios para la realización de este tipo de obras. Todas estas circunstancias llevaron a la aniquilación del subsuelo por la sobreexplotación y a la aparición de los graves problemas de abastecimiento a las poblaciones españolas que comienzan a hacerse visibles a inicios del siglo XX.

A esto hay que añadir la lucha e influencia mantenida por dos cuerpos de funcionarios del Estado: los Ingenieros de Minas y los de Obras Públicas, enfrentados por la gestión y control en las concesiones de licencias para alumbramientos de aguas. En síntesis, no hubo un cuerpo legal estructurado y homogéneo, sino que a medida que surgían las dudas, problemas y conflictos se dictaban normas.

La primera norma data del año 1841, cuando, debido a las protestas realizadas por empresas mineras de la provincia de Murcia a causa de la propiedad de las aguas alumbradas, se dictó una Real Orden estableciendo reglas que fijaban disposiciones.

Las aguas, como todo aquello que el minero extrajera de la mina, era de su propiedad mientras no perdiera el derecho que le concedía la ley, sin que tuviera que pagar canon alguno por el aprovechamiento de dichas aguas, pues tanto para extraerla como para darles salida ha tenido que realizar gastos económicos considerables. A la vez indicaba que cuando el minero perdía el derecho a la mina también lo hacía sobre el agua, pasando a ser del Estado mientras no existieran licitadores que denunciaran.

Este principio que le da la propiedad de las aguas alumbradas al minero que la extrajera, al igual que la pérdida en caso de abandono, tiene vigencia durante todo este período (GAY, 1921: 25).

Esto es un dato evidente de la falta de claridad en la legislación, pues con dicha actuación el Estado vulnera la competencia administrativa al conceder al 
minero la propiedad de las captaciones subterráneas, cuando ello correspondía a los Tribunales de Justicia como así sucedería en el futuro.

Como hemos indicado, el Estado siempre prefirió conceder a empresas (CArnero y Nuez, 2003; Pérez, 2001: 403-412) y a particulares los trabajos de aprovechamientos de aguas y de la ejecución de las obras necesarias para su conducción y almacenamiento: embalses, canales, acequias, etc., que se realizaron de forma directa. La concesión de aguas estaba supeditada a las condiciones que se establecían entre ambas partes; por ejemplo, en el caso de las heredades las concesiones de las aguas alumbradas (AgUILERA y CRISTOPHER, 1989; FELIP,1878) en terrenos públicos, se les otorgaba por un período de noventa y nueve años. El espíritu que prevaleció fue el del Real Decreto Instrucción de 10 de octubre de 1845, que regulaba las obras públicas y manifestaba que el Estado debía conferir su realización a empresas y particulares. ${ }^{4}$ En este caso, los solicitantes debían presentar la siguiente documentación: planos generales y específicos y la memoria del proyecto con la descripción detallada de las obras a realizar y el método de construcción, así como el plazo de ejecución y los resultados y ventajas que se pretendían lograr.

En las obras de ámbito estatal, provincial y municipal, una vez estudiadas todas las propuestas tanto de empresas como de particulares, las reclamaciones las resolvía el jefe político con el asesoramiento del Ingeniero Jefe. En las ejecutadas directamente por las distintas administraciones, corrían a cargo de sus propios técnicos. Comienza a plasmarse en forma de norma el influjo y poder ejercido durante toda esta época por los dos cuerpos de funcionarios del Estado, antes mencionados. De ahí que frente a una disposición de rango minero inmediatamente surja otra de características opuestas. Todo ello generó mucha confusión en la tramitación de los expedientes de alumbramientos. Como ejemplo:

Una prueba la tenemos en la Real Orden que dicta el Ministerio de Comercio, Instrucción y Obras Públicas el 14 de marzo del año 1846, del que era ministro Bravo Murillo, con el objetivo de dar respuesta a las dudas, dificultades y conflictos surgidos en torno a los aprovechamientos privados de aguas corrientes y públicas. En la que se indicaba que las concesiones tenían un período de caducidad que estaba establecido en seis meses, debiendo acreditar dicha situación ante el Jefe político, previo informe del Ingeniero de Distrito y de la Junta de Agricultura, perdiéndose el derecho sobre aquellas concesiones otorgadas cuando se interrumpían, desistían o cesaban en su aplicación. Los Jefes políticos y los funcionarios eran los encargados de contribuir con el Gobierno, para lograr la máxima equidad y provecho en las concesiones de autorizaciones para alumbrar aguas en terrenos y espacios de dominio público, ya que, en terrenos de propiedad particular, su propietario podía realizar estas labores libremente, no pudiendo intervenir el Estado, sino en el caso excepcional que se atentara o fuera nociva para la salud pública (AbeLLA, 1877: 214216).

En este devenir histórico sobre las condiciones dispuestas en los procedimientos para alumbramientos de aguas, el 24 de junio de 1849 se publica

4 La Gaceta de Madrid, de 11 de febrero de 1846, pp. 1-2. 
una Ley que implanta nuevas reglas y una serie de beneficios fiscales. Esta norma supuso la exención de tributos a los nuevos riegos con la excepción en las obras en que se haga uso de las aguas públicas, donde se necesita previamente la concesión Real. ${ }^{5}$ Tras su promulgación, la instrucción de los expedientes le correspondía al Ministerio de Comercio Instrucción y Obras Públicas. Estos constaban de una solicitud formulada por el peticionario donde indicaba los beneficios que esa agua le iba a proporcionar a su finca y al número de años de exención de tributos al que aspiraba. Para lograrlo era necesario un informe favorable de la Junta de Agricultura. Los mismos trámites se realizaban para las dispensas de contribuciones en riegos y artefactos que se planteaban con aguas alumbradas o de propiedades particulares. No se daba curso a ninguna solicitud sobre exenciones de contribuciones hasta que las obras estuvieran finalizadas. A continuación, se pasaba el expediente al Ministerio de Hacienda, que era el que declaraba la exoneración y dictaba las órdenes oportunas para su ejecución.

La falta de previsión y de un profundo estudio en materia de aguas se va poniendo de manifiesto a medida que pasan los años y a ello se debe el que una materia vital continuara regulándose a base de decretos, órdenes, etc. Ejemplo de ello es el Real Decreto del año 1859, que recoge el papel desempeñado por el Estado en el proceso privatizador de las aguas en espacios de dominio público. ${ }^{6}$ Esta norma estableció nuevos requisitos en los trámites de autorizaciones para la concesión de captaciones de aguas subterráneas (MARTín, 1989: 54-62), que se concretaban en la necesaria autorización real para cualquier empresa de interés público o privado que tuviera como objeto la obtención de dichas aguas, siempre que para su alumbramiento se hubieran de realizar calicatas, minas o investigaciones en terrenos del Estado o del Común, cuando no pertenecieran a particulares. Por otro lado, las aguas alumbradas y sacadas a la superficie mediante investigaciones, pozos o minas abiertas en terrenos del Estado o del Común con las correspondientes autorizaciones, eran propiedad del inventor, quien podía disponer libremente de ellas a perpetuidad como mejor le conviniera.

El Estado continuó su línea de producción normativa, si bien en el Real Decreto de 29 de abril de 1860 modifica lo dispuesto el año anterior, determinando que las concesiones por parte de la Administración debían tener carácter interino hasta la realización de un estudio más profundo. Es en este momento cuando se plantea la necesidad de disponer de estudios hidrológicos, aunque, como veremos más adelante, la medida es ambigua y llega tarde.

Esta disposición reguladora de las concesiones en terrenos del Estado y del Común (MAREu, 1996; MARTíN, 1997), estableció la necesaria autorización real para el alumbramiento de aguas en dichos terrenos, dándose siempre los permisos, sin perjuicios a terceros ni del derecho de propiedad, mediante Real Decreto, cuando las empresas eran de utilidad pública y hubieran o hubiesen de gozar de los beneficios de los que disfrutaban las obras de estas clases, y por Real

5 Siempre que las rentas de capitales se dediquen a las construcciones de obras públicas, acequias, canales, etc. que hagan uso de aguas públicas para regar terrenos tanto propios como ajenos.

6 Boletín oficial de la provincia de Canarias, $\mathrm{n}^{\circ}$ 62, de 23 de mayo de 1860, y Gaceta de Madrid, de 6 de mayo de 1860 . 
Orden expedida por el Ministerio de Fomento, cuando su objeto fuese de interés privado. Tanto en un caso como en el otro se debían instruir los correspondientes expedientes en el Gobierno de la provincia. Sirva de ejemplo:

En cuanto a las concesiones de aguas públicas para riegos, hecha individual o colectivamente a los propietarios de tierras eran a perpetuidad, mientras que las que se hacían a empresas o a individuos para regar tierras ajenas, pagaban un canon durante un número determinados de años, transcurridos los cuáles desaparecía el gravamen. En toda concesión se expresaba por hectáreas la extensión de terrenos que se pretendían regar y se fijaban los metros cúbicos y la cantidad de agua que se concedía. Cuando el caudal no se podía fijar o contemplar en la solicitud se entendía que era el necesario. Si las circunstancias lo permitían, los Ingenieros de Caminos Canales y Puertos realizaban una visita a las obras y determinaban la cantidad de agua para cada uno de los solicitantes. ${ }^{7}$

El 18 de diciembre de 1865, con el objeto de buscar mejores criterios en la administración de las captaciones de aguas, el entonces Director General de Obras Públicas, Vega de Armijo, redactó una circular estableciendo nuevas reglas para la instrucción de los aprovechamientos de aguas en las que se introducían algunas novedades que antes de anunciarse al público los aprovechamientos de aguas, ya sean de particulares como de empresas, previamente debían ser remitidos al Gobernador para que, a su vez, se pasasen a informe de los ingenieros de la provincia, en el que harían constar aquellos datos que considerasen oportunos e importantes. Del mismo modo, cuando algún particular o empresa precisaba ocupar terrenos de propiedad privada para llevar a cabo cualquier proyecto de aprovechamiento de aguas, allí donde no era preceptiva procediera la declaración de utilidad pública o servidumbre de acueducto contemplada en la Ley de 24 de junio de 1849, tenían que acreditar ante el Gobernador el correspondiente permiso o consentimiento de los dueños de los terrenos; en caso contrario, se devolvía el proyecto a los dueños:

Los proyectos constaban de una memoria y de planos explicativos. En caso de que los ingenieros consideraran oportuno realizar modificaciones, se lo comunicaban al Gobernador, que, a su vez, se lo notificaba a los interesados, los cuales debían responder si las aceptaban o no. A partir de entonces, todas las autorizaciones se publicaban en la Gaceta de Madrid, a excepción de las concedidas por los Gobernadores que se anunciaba en los Boletines Oficiales de cada provincia. En el caso de Canarias, en el Boletín Oficial de la Provincia (B.O.P.C.). Tanto unas como otras estaban vigiladas por el Ingeniero de la Provincia. Concluidas las obras, estos funcionarios remitían una certificación a la Dirección General de Obras Públicas exponiendo que se había cumplido con las condiciones establecidas en la autorización. Además, en el mes de enero estaban obligados a expedir un informe sobre el estado de las construcciones que se ejecutaban, bajo su vigilancia o control técnico. ${ }^{8}$

7 La Gaceta de Madrid, de 6 de mayo de 1860.

8 La Gaceta de Madrid, $\mathrm{n}^{\circ}$ 354, de 20 de diciembre de 1865. 
La publicación de la Ley de Aguas de 3 de agosto de 1866 aportó nuevas instrucciones sobre los trámites a realizar para la concesión de aguas subterráneas. La citada Ley no solo hace la distinción entre pozos ordinarios, caracterizados por su escasa profundidad y cuya agua se destinaba a usos domésticos, y pozos artesianos, de medianas y grandes profundidades y cuya agua alumbrada se destinaba al riego de terrenos o abastecimientos, sino que encomienda las competencias de todo este proceso en manos de los ayuntamientos. De acuerdo con lo establecido en los artículos 34 y 46, correspondía a los ayuntamientos la concesión de las licencias para abrir pozos ordinarios o norias en terrenos públicos, dando la plena propiedad de las aguas a quien las obtenía. ${ }^{9}$ El alumbramiento de aguas subterráneas por un particular mediante pozos artesianos, galerías, socavones, etc., también daba su propiedad a perpetuidad, con independencia de que las aguas salieran fuera de su finca.

En cualquier caso, y siempre que no distrajeran aguas públicas de su corriente natural, el dueño de un terreno podía alumbrar y apropiarse plenamente de las aguas existentes debajo de la superficie de su finca por medio de pozos artesianos, galerías, etc. Ante la denuncia por parte de un ayuntamiento o de regantes por la amenaza o peligro inminente de una disminución o merma de agua de corrientes públicas para el abastecimiento o el riego, se realizaba una inspección y, en caso de confirmarse dicha circunstancia, el Gobierno anulaba la autorización. Esta norma era también aplicable a las licencias concedidas por las Administraciones públicas en terrenos del Estado.

En terrenos ajenos o del Estado no podían realizarse obras en busca de aguas subterráneas sin los correspondientes permisos de los propietarios de dichos terrenos donde se pretendían realizar. Ello era así porque las solicitudes debían contener el lugar o paraje donde se iban a realizar los trabajos y la superficie del terreno destinada para la ejecución de dichas operaciones. Previo a la aprobación de la concesión, los beneficiarios debían depositar una fianza en metálico que oscilaba de entre los 100 y los 2.000 escudos para hacer frente a los posibles daños que se pudieran ocasionar.

Otorgada la concesión, se demarcaba el espacio en una zona paralelográmica al objeto de que no se pudieran realizar iguales exploraciones en él. La apertura o construcción de galerías no podía sobrepasar las 4 hectáreas de extensión (40.000 m) y los pozos artesianos las 1.000 hectáreas (10.000.000 de m). Se permitía que un individuo pudiese pedir y obtener autorización para ejecutar obras en diversas zonas.

Transcurridos seis meses desde la concesión de la autorización para ejecutar o llevar a cabo las obras subterráneas, el concesionario formalizaba la solicitud para la elaboración del proyecto consistente en una memoria explicativa y planos. Instruido el expediente, se procedía a su anuncio o publicación en el Boletín Oficial de la Provincia, encargándose de su resolución el Gobernador civil previo informe del Ingeniero Jefe de Minas. Las licencias podían caducar por no haber finalizado los trabajos de alumbramiento en el tiempo concedido o porque, una

9 La Gaceta de Madrid, nº 219, de 7 de agosto de 1866, pp. 1-4. 
vez concluidos y habiendo logrado la propiedad, los abandonaban, quedando las obras cegadas y las aguas inutilizadas.

Aunque la Ley de Aguas de 3 agosto de 1866 venía a dar cobertura legal a los aprovechamientos de aguas preexistentes (OJEDA y MACÍAS, 1989; MACíAS, 1990) su contenido no contribuyó a disminuir la conflictividad social, el incumplimiento en los procedimientos y la confusión suscitada en torno al proceso que debía seguirse en la tramitación de los expedientes de solicitud de permisos para alumbrar aguas.

Para resolver y acabar con las dudas que generaba el proceso se dictó una nueva norma, el Decreto Ley de Bases Generales para una Nueva Legislación de Minas de 29 de diciembre de 1868, en el que se incluyen nuevas pautas para la tramitación de expedientes y, en concreto, que para conseguir la propiedad de cuatro o más pertenencias mineras había que acudir al Gobernador explicando con claridad en la solicitud todas las circunstancias de la concesión pretendida. A continuación, y previa la publicidad necesaria, el Gobernador escuchaba las reclamaciones presentadas, disponiendo se demarcase y otorgase la licencia en un plazo no superior de cuatro meses, a contar desde la fecha de presentación del escrito o solicitud. Esta normativa no clarificó los trámites de las concesiones, pues, bajo el concepto genérico de "pertenencias mineras», los especuladores del subsuelo se harán con el control de muchas zonas en diversos territorios o lugares, favoreciendo el monopolio del agua. ${ }^{10}$

La aplicación de este Decreto no resolvió las dudas sobre las diligencias a seguir para los permisos de alumbramientos de aguas; por el contrario, generó un mayor desconcierto al no establecer con claridad si las reglas a seguir en dichos procesos eran las indicadas en la Ley de Aguas de 3 de agosto de 1866 o las del citado Decreto de diciembre de 1868. Ante la incertidumbre creada, el Gobernador de Canarias debió dirigirse en 1871 al Ministerio de Agricultura Industria y Comercio solicitando aclaración sobre que norma había de aplicarse (ABELlA, 1877: 129-131). La respuesta se concretó en la Real Orden de 30 de marzo de $1872^{11}$ haciendo distinción entre dos maneras o periodos para despachar los expedientes de alumbramientos de aguas subterráneas, en función de si el alumbramiento se había producido mientras se aplicaba lo estipulado en el Decreto de 1868 o si una vez las aguas alumbradas en la superficie se gestionaba por lo prescrito en la Ley de Aguas de 3 de agosto de 1866.

Así las cosas, la normativa sobre aguas siguió su curso, expidiéndose una Real Orden en 1875 por el Ministerio de Ultramar que trataba de facilitar a empresas y particulares la instrucción de peticiones de concesiones de aguas, estableciendo nuevos criterios tales como que:

Los proyectos presentados por los peticionarios debían estar completos para dar una idea exacta y completa de lo que se pretendía con la obra, acompañada de planos perfectamente legibles, lugar de emplazamiento, así como, los objetos o propiedades que pudieran ser susceptible de plantear reclamaciones $\mathrm{u}$ oposiciones

10 La Gaceta de Madrid, $\mathrm{n}^{\circ}$ 1, de 1 de enero de 1869, pp. 1-2.

11 La Gaceta de Madrid, nº 113, de 22 de abril de 1872, p. 207. 
a las concesiones. Seguidamente dichos planes pasaban a la inspección de Obras Públicas, que informaba si tenían todos los documentos, antes de dar publicidad a las oposiciones o reclamaciones de los recurrentes. ${ }^{12}$

Apenas unos años más tarde, el 13 de junio de 1879, se promulgó la segunda Ley de Aguas, conteniendo nuevas directrices. La concesión de la propiedad de las aguas alumbradas de los pozos ordinarios a los propietarios de los terrenos; y cuando estos trabajos se llevaban a cabo en terrenos públicos era el Gobernador quien concedía la autorización. Cualquier propietario de fincas podía abrir libremente todos los pozos ordinarios que quisiera, conservando la distancia de dos metros entre pozo y pozo y quince metros entre poblaciones, aunque disminuyera el agua de sus vecinos. Sin embargo, en las aguas alumbradas mediante pozos artesianos, galerías o socavones, el «buscador» o «alumbrador» era dueño a perpetuidad, con independencia del curso que tomaran o que salieran de sus terrenos, excepto cuando se causaba perjuicio en aguas públicas o privadas, en que las captaciones eran inmediatamente paralizadas por providencia dictada por los ayuntamientos, ya sea por iniciativa propia o por denuncia de los vecinos. Dicha providencia podía ser recurrida ante el Gobernador, quien previa audiencia de los interesados e informe pericial, dictaba resolución:

Todas estas obras no podían ejecutarse a menos de cuarenta (40) metros de edificios ajenos, carreteras, etc., ni a menos de cien (100) metros de otro alumbramiento, ni tampoco dentro de una pertenencia minera. Por otro lado, los permisos para alumbrar aguas en terrenos de dominio público correspondían a la Administración, en concreto al Gobernador y diversos Ministerios que por regla general asumían lo que informaba el Gobernador. En el caso de las minas y galerías o socavones, el dueño mantenía la propiedad mientras permanecieran en explotación, se mantiene lo indicado para estos casos desde el año $1841 .^{13}$

Así pues, esta segunda Ley de Aguas no estableció unos preceptos estrictos y claros, sino que contribuyó a liberar aún más el subsuelo para que todo propietario de tierras pudiera realizar cuantos alumbramientos estimara oportunos, contribuyendo a la sobreexplotación del subsuelo y a su destrucción.

Con la publicación dela Real Instrucción de 5 dejunio de 1883, la administración se dotó de un cuerpo legal que dio claridad y solidez a los procedimientos que debían seguirse en las concesiones hidráulicas, estando vigente hasta primer tercio del siglo xx.

Los particulares o empresas que deseaban realizar obras de alumbramientos de aguas debían presentar una solicitud en el Gobierno de la Provincia dirigida al Ministerio de Fomento, indicando dónde se iban a ejecutar las obras, acompañada del proyecto que constaba de una memoria explicativa donde señalaba el destino que tendría el agua alumbrada, las zonas y términos a los que afectaban los trabajos, así como las construcciones que se pensaban realizar: galerías y estanques para su

12 La Gaceta de Madrid, no 343 , de 9 de diciembre de 1875, p. 621.

13 La Gaceta de Madrid, n 170, de 19 de junio de 1879, pp. 799-805. 
almacenamiento. $^{14}$

También se incluía un plano general del terreno o zona de alumbramiento en el que se detallan los aspectos básicos de las construcciones u obras a realizar, un dibujo de los aprovechamientos existentes, corrientes de aguas naturales y artificiales, fuentes, pozos, manantiales, charcas, abrevaderos, caminos y minas que existían en toda la extensión de dichas zonas, y un presupuesto global conteniendo el coste total de la obra y otro específico en el que señalara el gasto en materiales, dirección facultativa, salario de los trabajadores, etc. Asimismo, se le adjuntaba la carta de pago, acreditativa de haber depositado el $1 \%$ del presupuesto en concepto de fianza, cuya devolución se haría una vez finalizados los trabajos.

Del registro de las solicitudes se encargaban en las Secciones de Fomento de cada provincia, ${ }^{15}$ entregándosele una copia al interesado. En el plazo de tres días pasaban a los Ingenieros Jefes de Minas, Caminos, Canales y Puertos, quienes informaban en los seis días siguientes que el expediente contenía todos los documentos y se ajustaban a la legalidad para su instrucción. De no ser así, los interesados tenían un plazo de tres días para la corrección o ampliación de documentos, pudiendo cambiar el proyecto o realizar las alegaciones $\mathrm{u}$ observaciones oportunas. De ser desestimadas por el Gobernador, el interesado, en el plazo de ocho días, podía apelar ante el Ministerio de Fomento, a cuyo ministerio también debía elevarse el expediente cuando el Gobernador discrepaba de la opinión facultativa, y para que se emitiera la Resolución que procediera en uno $u$ otro trámite. Si el interesado reconocía fallos en los documentos presentados, perdía todo derecho de prioridad y debía iniciar de nuevo el proceso con la presentación de documentos.

Cerrado el expediente, por orden del Gobernador se procedía a la publicación de la petición en el Boletín Oficial de la Provincia, dando un plazo de treinta días para reclamaciones, en cuyo tiempo el expediente estaba a disposición de los interesados en la Sección de Fomento:

El anuncio contenía los siguientes datos: Nombre y apellidos del solicitante, objeto de la petición, situación y extensión de los terrenos donde se quería actuar, los aprovechamientos que podían verse afectados, dueños, usuarios y concesionarios que pudieran considerarse afectados. A estos se les debía comunicar directamente la petición, mientras que a los Alcaldes se les remitía copia del anuncio para su colocación en los lugares de costumbre. ${ }^{16}$

Las reclamaciones se podían presentar a partir del tercer día de su publicación, comunicándoselo al peticionario para que en el plazo de quince días respondiera a las mismas, pudiendo ampliarse este periodo otros quince días más, previo permiso del Gobernador. Finalizada y recogida toda la información,

14 La Gaceta de Madrid, $\mathrm{n}^{\circ}$ 181, de 30 de junio de 1883, p. 800.

15 Fueron creadas por Real Decreto de 12 de junio de 1859. La Gaceta de Madrid, de 13 de junio de 1859, siendo suspendidas en sus funciones en el año 1877.

16 El Distrito Minero de Canarias se crea por Real Orden de 29 de junio de 1877, siendo su primer ingeniero de Minas don José Margarit. Boletín oficial de la provincia de Canarias, n⿳0 90, del año 1877. 
el Gobernador civil pasaba el expediente al Ingeniero Jefe de Minas, Caminos, Canales y Puertos, para que realizara el reconocimiento del terreno donde se iban a efectuar los trabajos, pudiendo delegar esta misión en un ingeniero que estuviera a sus órdenes. En el reconocimiento podían estar presentes el solicitante o peticionario y los reclamantes, ya sea de manera presencial o enviando personas en su representación, corriendo los gastos de las visitas de los ingenieros a cargo del peticionario. Si la visita era realizada por los Ingenieros Jefes solo se emitiría un informe al Gobernador, pero si asistían los ingenieros subalternos, cada uno firmaba el suyo.

En las visitas o reconocimientos se trataba de comprobar si el proyecto se ajustaba a la realidad, si era posible el alumbramiento de agua, sus ventajas e inconvenientes, la veracidad de las oposiciones, el plazo para comenzar las obras y su finalización. Estos informes tenían que dictarse en un espacio de treinta días, aunque de manera excepcional, previa petición, el Gobernador podía ampliar el plazo a sesenta días. De observarse que las obras podían afectar a algún servicio público que no dependía del Ingeniero de Caminos, Canales, Puertos y Minas, en el plazo de treinta días se daba conocimiento al funcionario encargado de dicho servicio en la provincia:

Realizados los informes facultativos y especiales, el Gobernador escuchaba la opinión de la Junta Provincial de Agricultura, Industria y Comercio, sobre la parte del expediente que afectaba a los intereses confiados a su cargo y respecto de la utilidad y conveniencia de las obras, así como a la Comisión Provincial, acerca de las oposiciones presentadas y su procedencia legal. Completado el expediente se enviaba al Ministerio de Fomento para que emitiera la consecuente resolución. Todas las instituciones disponían de un plazo de diez días para cumplir con sus atribuciones en esta materia. ${ }^{17}$

A partir de este momento, la tramitación del expediente corre a cargo de la Dirección General de Obras Públicas, oídas las Juntas Consultivas de Caminos, Canales, Puertos y Minas, y, si fuera el caso, los Centros Superiores a los que afectaba la concesión. Ésta podía ser denegada o concedida y, en este caso, la Real Orden que se expida debía considerar los límites y extensión de la zona concedida, los plazos para comenzar y concluir las obras y el depósito de una fianza que no podía ser superior al 3\% del presupuesto. Previo a la expedición de dicha Real Orden, las instituciones o corporaciones antes citadas hacían un informe dando a conocer al peticionario las condiciones para la concesión, a fin de obtener su conformidad y, en caso contrario, denegar la licencia.

Por su parte, los permisos para investigación por medio de calicatas o sondeos se solicitaban al Gobernador, adjuntando un plano con señalización de la zona donde se iban a practicar los trabajos y una breve reseña de lo que se pretendía realizar. Solicitado informe, en un plazo que oscilaba entre los tres y veinte días, a los Ingenieros de Caminos, Canales, Puertos, Minas, Montes y la Comandancia de Marina, en función de si se trataba de una zona de montes o

17 La Gaceta de Madrid, de 30 de junio de 1883. 
marítima, el Gobernador concedía la licencia teniendo en cuenta la extensión del terreno, el lugar y la fecha que disponía para presentar el proyecto, no pudiendo superar los tres meses, así como el depósito de una fianza para reparar los daños que se pudieran causar.

Cuando se trataba del aprovechamiento de aguas subálveas en los cauces de dominio público y por los medios señalados en el artículo 192 de la Ley de Aguas de 13 de junio de 1879, era de aplicación lo dispuesto en esta Real Orden, sin más variación que la no intervención en el expediente de los Ingenieros de Caminos, Canales, Puertos y Minas. En los alumbramientos de aguas subálveas en terrenos del Estado, los trámites seguidos eran los mismos que para los de dominio privado, con la salvedad que en el período de información pública debía oírse a la Delegación de Hacienda de la provincia, encargada de elaborar un informe sobre la procedencia de la petición y condiciones en las que podía accederse para poner a salvo los intereses y derechos del Estado. Esta regla nunca se llevó a efecto.

En las captaciones en los terrenos de propios o del común de los pueblos, los trámites aplicados eran los previstos en esta Real Orden Instrucción de 5 de junio de 1883, con informe detallado por parte de los ayuntamientos afectados. En ambos casos, las autorizaciones las concedía el Consejo de Ministros, a propuesta del Ministerio de Fomento. Terminadas las operaciones del alumbramiento, el Ministerio de Fomento expedía al concesionario el título de propiedad de las aguas. Para su posterior aprovechamiento sería considerada como de su exclusiva propiedad, pudiendo solicitar para conducirlas la declaración de utilidad pública o la imposición de las servidumbres legales.

Los expedientes de tramitación se adecuaban a lo previsto en esta Real Orden Instrucción ya señalada en el párrafo anterior, con arreglo a lo cual se otorgaba o negaba la concesión. Para ello, los peticionarios disponían de un período de seis meses para completar los datos y conservar los derechos de prioridad que tenían conservados. En caso de que el peticionario no residiera en la provincia donde quería llevar a cabo los trabajos de alumbramientos de agua, debía nombrar a un representante con poderes para tramitar toda la documentación.

Tras la Instrucción de 5 de junio de 1883 en la que se disponía que las autorizaciones para el alumbramiento de aguas debían ajustarse a lo dispuesto en la Ley de 13 de junio de 1879, hasta el siglo xx no se vuelve a legislar sobre los trámites a seguir en las concesiones de aguas subterráneas para usos tales como el abastecimiento a poblaciones, sanitarios, etc. Así, el 28 de enero del año 1900, la Dirección de Obras Públicas, Comercio y Minas publicó una Real Orden dirigida a los gobernadores sobre los procedimientos a realizar en los aprovechamientos de las aguas públicas. ${ }^{18}$ Con carácter general se les hizo saber que en la tramitación de dichos expedientes era de aplicación lo estipulado en el artículo 97 de la Ley General de Obras Públicas, que decía que, antes de recaer o dictar resolución, el Ministerio de Fomento elegiría la que mejor representaba o defendiera los intereses públicos, llevando a cabo para ello una información pública de todos los proyectos que competían entre sí. Se pasó así de un liberalismo total en materia

18 Boletín oficial de la provincia de Canarias n²9, del año 1900. 
de captaciones de aguas subterráneas a un leve intento de intervencionismo del Estado, originado por los problemas de abastecimiento que comienzan a surgir en los grandes núcleos urbanos fruto del aumento de población.

Cuatro años más tarde, el 6 de febrero de 1904, el Ingeniero Jefe del Servicio Agronómico de Canarias $^{19}$ planteó al Ministerio de Agricultura, Industria, Comercio y Obras Públicas, que, en la tramitación de los expedientes, fueran necesarios sus informes para otorgar cualquier concesión. Más tarde, el 28 de junio de 1910, se dictó un Real Decreto para los alumbramientos de aguas por parte del Estado y la concesión de ayudas en el ámbito informativo:

\begin{abstract}
Si la explotación la pretendía realizar un particular le asesoraba el Instituto Geológico de España, facilitándole toda la documentación e información que poseyera y si era una Corporación o Empresa, se realizaba un estudio muy detallado de la localidad donde se pretendía ejecutar dichos trabajos, pronunciándose al efecto dicho Instituto. ${ }^{20}$
\end{abstract}

Al tiempo, aparecen las subvenciones conocidas con el nombre de auxilios y destinadas a particulares y empresas. Para acceder a dichos auxilios se exigió el requisito de que las aguas alumbradas se destinaran al abastecimiento de las poblaciones (DE LEÓN,1921: 3-27). En el caso de las corporaciones o entidades empresas, heredades sociedades, etc. (HERnÁNDEZ, 1954), la asignación podía alcanzar hasta el 50\% del total del presupuesto de las obras y para su adjudicación era preceptivo contar con el informe favorable del Instituto Geológico. Así pues, de una primera etapa en la que las peticiones o solicitudes de explotación de aguas subterráneas, al igual que los trámites establecidos para las concesiones, tienen un objetivo esencial la agricultura y el riego de terrenos, se pasa o evoluciona a una segunda en la abastecimiento de las poblaciones es el objetivo prioritario, contando con el respaldo del Estado tanto desde el punto de vista informativo facilitando los trámites a seguir como económico asignando partidas en los Presupuestos Generales del Estado. La consecuencia fue una avalancha de solicitudes a las que el Estado no pudo hacer frente, originándose una reducción del ámbito de las concesiones, una limitación a los proyectos destinados a abastecer poblaciones y a la ejecución de estudios o investigaciones de aquellas cuencas donde no se habían realizado explotaciones.

A partir de entonces se implantó un nuevo modelo en la tramitación para la obtención de las licencias de alumbramientos de aguas, siendo el Instituto Geológico de España el que establecía las condiciones y enviaba todos los proyectos con sus correspondientes presupuestos a la Dirección General de Agricultura.

El Estado, por su parte, podía alumbrar aguas libremente en sus propiedades e incluso en terrenos de particulares, llegando a la expropiación forzosa si era necesario. Igualmente podía auxiliar a corporaciones, empresas y particulares siempre que, a juicio de la Comisión del Mapa Geológico, existieran posibilidades

19 El Servicio Agronómico en España se constituye por Real Orden de 16 de agosto de 1895 y desde entonces participaba activamente en la tramitación de los expedientes. La Gaceta de Madrid n ${ }^{\circ}$ 351, de 18 de diciembre de 1904.

20 La Gaceta de Madrid nº180, 29 de junio de 1910. 
de encontrar aguas. La propiedad de las mismas sería del alumbrador.

Concedidas las subvenciones, las instituciones beneficiadas debían comenzar los trabajos de acuerdo con lo establecido por la Administración, dándose por caducadas o acabadas las subvenciones cuando los concesionarios las abandonan o no las ejecutan en el plazo señalado y por indicación del Instituto Geológico de España o renuncia del solicitante. Del trámite se encargaba el Negociado de Minas de la Dirección General de Agricultura, Industria y Comercio.

Llegados a este punto, cabe plantearse si la promulgación del Real Decreto de 28 de junio de 1910 anulaba lo dispuesto en La Ley de Aguas de 13 de junio de 1879 e Instrucción de 5 de junio de 1883 en materia de la tramitación de los expedientes de concesiones de aguas subterráneas. En absoluto, ya que el procedimiento expuesto solo se refería a los alumbramientos realizados por el Estado. Lo establecido en la Ley y en la Instrucción estará en vigor hasta el primer tercio del siglo $x x$.

En 1912, un nuevo proyecto del Código Minero presentado en las Cortes trató de regular las aguas potables y minero-medicinales no apropiadas por los terratenientes mediante la apertura de pozos, socavones, sondeos. ${ }^{21}$

Fue en el capítulo vi, donde se estableció su clasificación de tal forma que las Aguas comunes, eran las dedicadas tanto al uso doméstico como a la agricultura, las minerales para usos industriales por no ser potables debido a los altos índices de sales y las minero-medicinales destinadas a fines curativos y sanitarios. ${ }^{22}$

Los expedientes instruidos como consecuencia de las diferencias surgidas entre propietarios particulares de aguas comunes obtenidas mediante la apertura de pozos, galerías, etc., en terrenos de propiedad privada, se tramitaban en la Jefatura de Minas de los Distritos donde se ubicaban los terrenos. Su personal facultativo hacía los reconocimientos y dictámenes preceptivos, correspondiendo al Ministerio de Agricultura Minas y Montes dictar las resoluciones definitivas. De producirse divergencias o discrepancias, los interesados podían dirimirlas acudiendo a los Tribunales de Justicia.

El propio Gobernador podía conceder, asimismo, autorización para llevar a cabo obras de alumbramiento de aguas mediante pozos, galerías y socavones en terrenos de dominio público, ya sean del Estado, de la provincia o de los municipios, tramitándose el expediente en la Oficina de Minas y quedando sujeto a lo que determinaba la Ley de Aguas sobre la limitación de los expedientes. De aquí la información de las Jefaturas de los Distritos sobre los terrenos en los que se trataban de dejar a salvo los aprovechamientos preexistentes, ya sean de interés público o privado, y cuantos derechos legítimamente adquiridos pudieran lesionarse.

Los mineros eran propietarios de toda clase de aguas que alumbraban mientras conservaban el dominio de sus concesiones. Pero, si en sus trabajos de búsqueda, no existiendo negligencias ni intención, se observaban desvíos de 
aguas ya alumbradas, debían ser paralizados y las aguas repuestas a su estado originario; de no hacerlo, el Gobernador, previo informe del Ingeniero Jefe de Minas, les sancionaba con el abono del sobreprecio. De existir intención de causar perjuicio en dichas explotaciones, además de las sanciones ya señaladas, el infractor quedaba sujeto a la responsabilidad que le correspondiera. Este tipo de situaciones fue frecuente en Canarias dado el carácter volcánico de la isla, a lo que se unían las desviaciones naturales de aguas alumbradas hacia espacios inferiores por causa de temporales o terremotos, originando una importante conflictividad de difícil solución entre propietarios originarios y definitivos.

La preferencia de las aguas minerales correspondía a los dueños de terrenos que pudieran alumbrarlas mediante galerías o socavones, sin necesidad de una concesión especial. En caso de no hacerlo, el Estado podía concederlas a quien primero lo solicitase. No se admitieron solicitudes de registros, sino que se optó por siempre pasar por el trámite de la investigación, previa la obtención del permiso necesario, consiguiéndose la concesión cuando el manantial fuera alumbrado por el investigador.

Los trámites de los permisos de investigación se limitaban a una solicitud conteniendo los campos comprendidos y el nombre de sus propietarios, adjuntando el consentimiento del dueño del terreno en el que se iban a iniciar los trabajos y un informe de la Jefatura del Distrito Forestal cuando se hicieran en suelo del Estado. Si en el proceso de investigación de aguas minerales aparecían aguas comunes, el dueño de la superficie podía optar entre hacerse dueño de las aguas comunes indemnizando al investigador por los gastos generados o bien disfrutar de los beneficios con el investigador sin más indemnización. En ambos casos, el dueño del terreno podía suspender las obras emprendidas y el investigador no podía emprender otras a una distancia horizontal menor de cien metros.

Las concesiones de las aguas minero-medicinales seguían los mismos trámites establecidos para las concesiones mineras, con la salvedad de transformarse en registro el permiso de investigación previamente concedido y la cancelación del expediente si a menos de cien metros de distancia horizontal existía un alumbramiento anterior a esta petición.

Los expedientes de licencias de aguas minero-medicinales se gestionaban y resolvían por el Ministerio de la Gobernación. Como hemos señalado, los mineros eran los dueños de todas las aguas que alumbraban, si bien en las mineromedicinales el Gobierno podía obligarles a que en un plazo determinado les dieran la correspondiente aplicación curativa o sanitaria. En caso de incumplimiento se ejecutaba la expropiación forzosa. Si el caudal de aguas no era suficiente para sus usos terapéuticos y mineros, las Direcciones Generales de Sanidad, Agricultura, Minas y Montes informaban en el expediente al objeto de determinar qué usos eran de mayor utilidad pública, resolviendo finalmente el Consejo de Ministro.

En los expedientes administrativos que se formaban sobre aguas subterráneas, se elevaba consulta al Instituto Geológico de España siempre y cuando se tratara de iluminación, captación, defensa y aprovechamiento de los manantiales mineromedicinales de orígenes subterráneos, sometidos por razón de salud pública 
a vigilancia y protección por parte del Gobierno. Del mismo modo, cuando se producía una expropiación forzosa de un manantial minero-medicinal, se daba audiencia al Consejo de Minería al objeto de tener amplios datos al respecto.

Dada la importancia e interés en la conservación de los manantiales mineromedicinales, por la Jefatura de Minas se estableció sobre los terrenos vecinos una servidumbre denominada Ámbito de Protección Variable. En esta demarcación no se hacían más excavaciones que las autorizadas para explotaciones agrícolas y construcciones de edificios. El ámbito de protección podía ser ampliado o restringido en cualquier momento mediante expediente, siempre que la oportunidad de la medida viniera acreditada por trabajos o estudios apropiados. La modificación de su perímetro debía ser solicitada por el propietario del manantial o por los dueños de las tierras que sufrían esta servidumbre, sin el perjuicio de la actuación de la Jefatura de Minas para promoverlas, con la audiencia de los interesados, cuando se estimaba indispensable.

En 1920, la Instrucción de 5 de junio de 1883 experimentó algunas modificaciones relativas al reconocimiento de utilidad pública en las captaciones de aguas subterráneas y a la aplicación de la expropiación forzosa, cuando la situación lo requería. ${ }^{23}$

La última de las disposiciones legislativas aquí reseñadas fue el Decreto Ley de 7 de enero de 1927 relativo a las concesiones hidráulicas en los montes de utilidad pública. En él se establece que solo se concederían licencias de aguas, públicas o privadas, cuando su objetivo fuera el abastecimiento de poblaciones (De León, 1921: 3-27; SÁnCHEZ-PINTO,1968: 123-126), y que las subvenciones públicas (SÁNCHEZ-PINTO,1968: 126-134) solo se darían a las nacidas en terrenos particulares o en montes propiedad de los pueblos o del Estado. ${ }^{24}$

Los expedientes de aprovechamientos de aguas que nacían en montes de propiedad municipal o del Estado, promovidos por particulares o empresas, tenían prioridad para obtener la concesión si manifestaban interés por los mismos y se comprometían a ejecutarlos en los plazos indicados.

Cuando el aprovechamiento del agua por parte de un particular se destinaba al abastecimiento, la autorización concedida para captarla comprendía, para evitar cualquier contaminación, desde su origen hasta llegar a los manantiales, e igual sucedía con las expropiaciones que fue necesario llevar a cabo tanto en propiedades privadas como públicas. A partir de este momento, la tramitación de los expedientes para los aprovechamientos de aguas se rige por lo dispuesto en este Real Decreto Ley.

El ingeniero de Montes Lillo Sanz estimó lesivos para los intereses del Estado y de los pueblos propietarios de los montes lo establecido en este Decreto Ley, al suponer que el objetivo y significación de la ley no era otro que la de resolver una competencia de jurisdicción entre ingenieros. ${ }^{25}$ Tal suposición viene a confirmar lo ya manifestado acerca de la lucha mantenida entre los dos cuerpos de

23 A partir de 1914 ya se llevaba a cabo, pero de una manera parcial en la tramitación de concesiones de aguas subterráneas.

24 La Gaceta de Madrid, ${ }^{\circ}$ 8, de 8 de enero de 1927.

25 Revista de Obras Públicas n 2471, del año 1927. 
ingenieros, los de Minas y los de Obras Públicas, que quisieron monopolizar los procedimientos de tramitación de expedientes para las concesiones, como lo pone de manifiesto la legislación dictada al efecto en los ámbitos legales y jurídicos y los distintos conflictos y litigios suscitados en todo el territorio nacional.

En síntesis, la abundante normativa aparecida a los largo del siglo XIX y primer tercio del siglo $x x$, no suficiente para reglar los aprovechamientos de aguas subterráneas en sus diversas tipologías, aunque se trata de un marco legal caracterizado por su diversidad de rangos, leyes, órdenes, decretos, circulares, etc., traspasó el territorio nacional y fue de aplicación en las colonias españolas de Cuba y Puerto Rico. ${ }^{26}$ En la isla de Cuba, en el año 1891, con la aplicación de la ley de 13 de junio de 187927 (GIl y Morales,1992:183-202) y en la isla de Puerto Rico, en 1886, con una Real Orden que establecía la instrucción de los aprovechamientos. Todo ello no evitó el esquilmo de los recursos hídricos por la sobreexplotación del subsuelo.

\section{EL MARCO ADMINISTRATIVO-INSTITUCIONAL}

El desarrollo legislativo lleva aparejado el surgimiento de diferentes organismos de carácter judicial, institucional o administrativo, llamados a desempeñar una importante función en todo el proceso de captaciones de aguas. Con la creación de los Tribunales de Justicia, los particulares, heredades, instituciones y sociedades pudieron dirimir los distintos conflictos que tuvieron como motivo el agua. A resolver la cuestión también contribuyeron otras instituciones de carácter territorial como los ayuntamientos, gobiernos civiles, diputaciones, etc. Así pues, conforme se fueron elaborando reglas para las autorizaciones de captaciones de agua, se fue configurando una estructura administrativa e institucional para facilitar la tramitación de los expedientes y solucionar los conflictos suscitados por la realización de estas obras, al tiempo que se delimita el marco competencial de las instituciones y Tribunales de Justicia.

El papel de los tribunales quedó organizado en los capítulos XVI y XV de las Leyes de Aguas de 3 de agosto de 1866 y de 13 de junio de 1879, respectivamente, siendo los de lo Contencioso-Administrativo los encargados del conocimiento de los recursos contra las providencias dictadas por la Administración en aquellos casos en que por dichas leyes se lastimaban derechos adquiridos, o que por disposiciones emanadas de la Administración se aplicaba una servidumbre forzosa a la propiedad privada o por alguna otra limitación o gravamen; en los casos previstos en esta Ley o bien por cuestiones que se suscitaban sobre resarcimientos de daños y perjuicios, etc. También tenían atribuciones en los asuntos relativos al dominio y posesión de las aguas privadas (MOREu, 1996) y de las cuestiones suscitada entre particulares sobre preferencias de derechos cuando se fundían en títulos de Derecho Civil, así como en los casos referentes a daños y perjuicios ocasionados a terceros en sus derechos de propiedad particular, cuya

26 La Gaceta de Madrid, $\mathrm{n}^{\circ}$ 111, de 21 de abril de 1866, p. 205.

27 La Gaceta de Madrid, nº11, de 11 de enero de 1891, pp. 123-128. 
enajenación no fuera forzosa, y por la apertura de pozos ordinarios artesianos y la ejecución de obras subterráneas.

La segunda Ley de Aguas de 13 de junio de 1879 incorporó nuevos aspectos dentro del marco competencial de los tribunales al establecer que eran de su competencia los casos en los que se declaraba la caducidad de una concesión hecha a particulares o empresas, de acuerdo a lo dispuesto en la Ley General de Obras Públicas del año $1877,{ }^{28}$ así como de los aspectos relacionados con el dominio de los álveos y de las servidumbres de dominio público y de paso.

Ahora bien, ni las disposiciones ni los organismos constituidos en torno a las captaciones de aguas, lograron detener los numerosos litigios y el expolio del subsuelo. El viejo «adagio» español de «quien hizo la ley hizo la trampa» parece haber tenido su eco en los alumbramientos de aguas, pues los usurpadores del subsuelo se valieron de diversas triquiñuelas legales para esquivar las normas y retrasar su aplicación. Así, obras declaradas ilegales por los Tribunales de Justicia, estuvieron en plena explotación durante bastante tiempo.

Sirvan de ejemplo la figura de los interdictos, uno de los recursos más utilizados por los demandantes. Se trata de procedimientos judiciales sencillos que conceden la posesión provisional de una cosa a una persona física o jurídica. Destaca por su protección y agilidad temporal. En general, cuando se presentaba, el juicio se celebraba en el plazo de tres días, con testigos que no sabían leer ni escribir y trabajadores del demandante, quien, para imposibilitar la defensa del demandado, depositaba una fianza que impedía a éste el aporte de pruebas justificativas y su defensa. Su tipología era diversa y oscila entre el de recobrar, cuyo objetivo era recuperar una posesión perdida, el de retener, que perseguía mantener una propiedad, y, por último, el de obra nueva, que intentaba la paralización de unos trabajos considerados perjudiciales para sus intereses.

A la labor desempeñada por los tribunales, se añade la de los jueces de primera instancia, vetados en ocasiones por ser parte interesada en el negocio del agua, debiendo inhibirse en la resolución de diversos conflictos. Aunque el marco legal hacía distinción entre las competencias administrativas y las judiciales, no siempre se logró obviar la confusión de ambas. Para disipar las dudas, se ordenó que los recursos administrativos se solventaran por esta vía y todo lo relativo a la propiedad, posesión, dominio y daños a terceros, lo fuera por la vía judicial.

De los interdictos sólo quedaron excluidas las providencias dictadas por los ayuntamientos, paralizando obras de alumbramientos que consideraban perjudiciales para sus intereses. Ello fue posible merced a la Real Orden de 8 de mayo de 1839 por la que también se puso límites a las atribuciones administrativas y judiciales. ${ }^{29}$

Con la reforma llevada a cabo por Javier de Burgos, el Estado se fue dotando de recursos humanos y administrativos. Valga como ejemplo las Secciones de Fomento, departamentos creados por Real Decreto de 12 de julio de 1859 dependientes del Ministerio de Fomento, donde se tramitaban los expedientes de alumbramientos de aguas, así como otros organismos como el Servicio

28 La Gaceta de Madrid, ${ }^{\circ}$ 188, de 7 de julio de 1877.

29 La Gaceta de Madrid, n 1844, de 17 de mayo de 1839. 
Agronómico (CARTAÑA, 2005: 265-268) y el Instituto Geológico de España. Estos organismos tuvieron una escasa repercusión en los procesos de alumbramientos de aguas al no frenar o parar la aniquilación y expolio del subsuelo.

Una posterior Real Orden de 30 de julio de 1865 estableció diez Divisiones Hidrológicas, ${ }^{30}$ a las que se añadieron por un Real Decreto de 15 de agosto, cinco más en las ciudades de Valladolid, Madrid, Ciudad Real, Córdoba y Zaragoza, no contemplándose ninguna para la Provincia de Canarias (MACUA, 1957: 8-46 y 46-61), (PALAu, 1875: 234-235). Este hecho supuso que no se realizaran estudios previos para saber de la idoneidad de las obras de alumbramientos de aguas públicas, minería, etc. ${ }^{31}$

En el ámbito institucional conviene resaltar las funciones y atribuciones de los gobernadores y los ayuntamientos. Los ayuntamientos, por su cercanía y defensa de los intereses de su pueblo, trataron de cumplir lo establecido en las Leyes de Aguas. Entre sus actuaciones destaca la suspensión mediante providencia de toda obra, ya sea mediante pozos artesianos, galerías o socavones, que mermaran las aguas públicas o privadas preexistentes, con independencia de su uso público o privado y con derechos legítimamente adquiridos. Ante estas situaciones, los alcaldes podían actuar de oficio o por denuncia de los vecinos. Del mismo modo, podían suspender las obras de alumbramientos llevadas a cabo por particulares o sociedades de aguas ( cuando sus técnicos facultativos informaban que no se respetaban las distancias legalmente establecidas y distraían aguas del servicio público (abastecimiento, riegos, abrevadero). Los afectados podían recurrir las providencias de los alcaldes ante el Gobernador, cuya resolución podía confirmarlas o revocarlas. En cualquier caso, los alcaldes solo tenían autoridad para suspender las obras pero no para inutilizar las ya realizadas. No obstante, se suscitaron competencias entre el órgano administrativo y el judicial. Las sentencias de 6 de julio de 1917 y de 8 de febrero de 1921 dejaron claro que era competencia del alcalde la suspensión de las obras.

Pero no siempre los alcaldes cumplieron con sus obligaciones y funciones en materia de aguas. Solicitada al Gobernador autorización para alumbrar aguas por un particular o sociedad de aguas (CARNERO y NUEZ, 2003), se remitía al ayuntamiento afectado un edicto dando publicidad a las obras a realizar para que los vecinos perjudicados presentaran escritos de oposición, remitidos al Gobernador tras treinta días de exposición pública. Algunos ayuntamientos hicieron caso omiso a los escritos de oposición e informaban de lo contrario al Gobernador. De aquí el que los problemas o dificultades de abastecimiento que sufrieron las poblaciones en los inicios del siglo $x x$ tuviese su origen en la conducta observada por dichos alcaldes en el siglo XIX, convirtiéndose en los mejores colaboradores y aliados de los explotadores de aguas.

Los Gobernadores de provincia van a desempeñar un papel relevante en los

30 La Gaceta de Madrid, n $^{\circ} 211$, de 30 de julio de 1865.

31 Boletín Oficial de la provincia de Canarias no 20, del año 1918. Hasta el día 31 de enero de 1917 en que es designado Alfonso Fernández para realizar un estudio hidrológico en la isla de Fuerteventura, acompañado por el ingeniero de Minas residente en Santa Cruz de Tenerife, no se produce una iniciativa estatal en esta materia en Canarias. 
alumbramientos de aguas al ser los representantes del Estado en cada territorio y los encargados de velar por el cumplimiento de la Ley. Entre sus atribuciones figuraban los expedientes de solicitudes de alumbramientos, disponiendo toda la documentación requerida para su aprobación, resolver las providencias de los ayuntamientos recurridas por particulares, heredades o asociaciones de aguas, comprobar que las obras ejecutadas se correspondían con las propuestas, disponer del personal de las Secciones de Fomento y solventar todas las cuestiones administrativas en torno a estas obras.

Sin embargo, su labor no fue todo lo eficiente que cabía esperar debido, sobre todo, a la confusión que en ocasiones se produjo entre sus atribuciones meramente administrativas y las de índole jurídica. Así se les ve intervenir en asuntos de propiedad, dominio y posesión de aguas, cuando en realidad eran competencia de los Tribunales de Justicia. Además, en muchos casos, son miembros de las élites explotadoras de aguas y parte interesada en dicho negocio. Fueron un factor más a tener en cuenta en la aniquilación del subsuelo, pues todos estaban inmersos en este mercado del agua (MACíAs, 1990).

Previamente a la figura de los Gobernadores, existieron otras figuras como los Jefes Superiores de las Provincias y Jefes Políticos, cuyas funciones fueron ordenadas por las Leyes de 2 de junio de 1813 y 3 de febrero de 1823 respectivamente, los Subgobernadores de Fomento, por el Real Decreto de 23 de octubre de 1833, y los Gobernadores Civiles en el de 13 de mayo del año 1834.

Sus atribuciones generales fueron indicadas en la Ley Provincial entre los artículos 14 y 30 y reguladas por una Ley de 25 de septiembre de $1863,{ }^{32}$ que organizaba el funcionamiento del Gobierno y Administración de las Provincias, en la cual también era de aplicación la Ley de 16 de agosto de 1841, donde las islas de Menorca y Gran Canaria podían disponer de un Subgobernador, previo informe del Consejo de Estado y del conocimiento de las Cortes, que en ningún caso tendría las atribuciones propias del Gobernador.

Sin embargo, su labor no fue todo lo eficiente que cabía esperar debido, sobre todo, a la confusión que en ocasiones se produjo entre sus atribuciones meramente administrativas y las de índole jurídica. Así se les ve intervenir en asuntos de propiedad, dominio y posesión de aguas, cuando en realidad eran competencia de los Tribunales de Justicia. Además, en muchos casos, son miembros de las élites explotadoras de aguas y parte interesada en dicho negocio. Fueron un factor más a tener en cuenta en la aniquilación o esquilmo del subsuelo, pues todos estaban inmersos en este mercado del agua.

Previa a la figura de los gobernadores, existieron otras figuras como los Jefes Superiores de las Provincias o Jefes Políticos, cuyas funciones fueron reguladas por las Leyes de 2 de junio de 1813 y 3 de febrero de 1823, respectivamente, los Subgobernadores de Fomento, por el Real Decreto de 23 de octubre de 1833, y los Gobernadores Civiles en el de 13 de mayo del año 1834. Sus atribuciones generales fueron indicadas en la Ley Provincial entre los artículos 14 y 30 y reguladas por

32 La Gaceta de Madrid, de 27 de septiembre de 1863. 
una Ley de 25 de septiembre de $1863,{ }^{33}$ que organizaba el funcionamiento del Gobierno y Administración de las Provincias, en la cual también era de aplicación la Ley de 16 de agosto de 1841, donde las islas de Menorca y Gran Canaria podían disponer de un Subgobernador, previo informe del Consejo de Estado y del conocimiento de las Cortes, que en ningún caso tendría las atribuciones propias del Gobernador. A pesar de estas limitaciones legales, realizaron funciones propias de los Gobernadores. Una demostración la vemos en el año $1873,{ }^{34}$ cuando se elogiaba la actitud del Subgobernador de Gran Canaria, que, sin contar con personal, despachaba todos los asuntos relacionados con la verificación de los trabajos mineros de galerías subterráneas en el subsuelo de la Isla que como se sabe, estaba declarado por las Leyes competencia del Estado. Con posterioridad, el 9 de febrero de 1874 el Ministerio de Fomento, a instancia de la Junta Superior Facultativa de Minas y de don Francisco Romero Cerdeña, decreta la cancelación de dicha institución.

\section{LOS TRÁMITES EN LOS ALUMBRAMIENTOS DE AGUAS EN GRAN CANARIA}

Tras la conquista de la isla de Gran Canaria e incorporación a la Corona de Castilla el 29 de abril de 1483, se produjeron los repartimientos de tierras y aguas entre los que participaron en la empresa con sus personas o desde el punto de vista financiero. Con la asignación de las aguas de las medianías y cumbres al riego de las tierras de costa, se formaron los primeros y principales heredamientos de agua (GUIMERÁ, 1957) de la isla. La disminución de la masa forestal ante el avance de las tierras de cultivo por el interior isleño supuso una disminución de los caudales de agua que bajaban hacía la costa. Para paliar esta escasez, a fines del siglo XVII se inicia la apertura de minas (SuÁrez, 1987: 534-55; 2014; HERnÁNDEZ, 2006:161) de agua en los cauces de los barrancos hasta que en el siglo XIX se introducen nuevas formas de captación de aguas subterráneas con la apertura de galerías y pozos ordinarios y artesianos. En su Diccionario Geográfico-Estadístico-Histórico, Pedro de Olive contabiliza en 1865 un total de 30 galerías y 1.170 pozos ordinarios (MADOz, 1845-1850: $\mathrm{xv}$ ), pues los de origen artesiano no se generalizan hasta fines del siglo XIX para alcanzar su total apogeo en el siglo XX. Estas obras fueron realizadas por particulares, heredades y asociaciones de aguas, instituciones religiosas y ayuntamientos. La legislación aplicada a los solicitantes o peticionarios de estas captaciones de aguas en Gran Canaria fue la misma que se aplicó para el resto del Estado, sin que se tuvieran en cuenta las características geofísicas de la isla (DíAz, 2013).

La aplicación de una legislación general no se vio compensada con un incremento de la dotación de recursos administrativos, humanos y logísticos. Así, por Real Orden de 30 de julio de 1865 se constituyeron diez Divisiones

33 La Gaceta de Madrid, de 27 de septiembre de 1863.

34 Periódico «La Afortunada» n 7, de 1873. 
Hidrológicas, ${ }^{35}$ ampliadas en cinco más por Real Decreto de 15 de agosto de 1876, sin que se contemplara ninguna para la provincia de Canarias, con lo que no se realizaron estudios previos para ver la idoneidad de las obras de alumbramientos de aguas. Los propios explotadores del subsuelo fueron los primeros interesados en que no se crearan divisiones hidrológicas pues veían en ellas un grave obstáculo para sus intereses especulativos

Con la Real Orden de 29 de junio de $1877^{36}$ se crea el Distrito Minero de Canarias, con sede en la ciudad de Las Palmas y don José Margarit Coll como primer Ingeniero de Minas, y aunque la legislación establecía que los proyectos tenían que ir firmados por Ingenieros de Minas, los expedientes provenientes de Gran Canaria incumplían la normativa al ir firmados por Ingenieros de Montes, Militares y Ayudantes de Obras Públicas, debido a la carencia de oficiales y escribientes en la Sección de Fomento, razón por la que Sociedad Económica de Amigos del País de Las Palmas eleva su protesta ante el Ministerio de Fomento, mostrando, por un lado, su malestar ante la paralización de innumerables expedientes de solicitud de pertenencias mineras y felicitando, por otro, al Subgobernador de Gran Canaria por el papel desempeñado en este ámbito a pesar de estar incumpliendo con la ley por carecer de competencias para ello.

En 1873 con el objetivo de subsanar estas deficiencias técnicas-administrativas, y gracias a las gestiones políticas realizadas por el diputado grancanario don Fernando León y Castillo, se constituye la Subsección de Fomento en Las Palmas de Gran Canaria, logrando así la independencia administrativa de la isla de Tenerife y consiguiendo además, en tiempos del gobernador don Salvador Muro, atribuciones propias de este cargo. Esta situación produjo una fuerte oposición desde la isla de Tenerife porque se sintieron despojados y acudieron al señor Echegaray, Ministro de Fomento, disponiendo este que, en lo concerniente a dicho ramo, el Subgobernador de Gran Canaria no tenía más facultades que la simple tramitación que el Gobierno de la Provincia le encomendaba.

Por otra parte, la inmensa mayoría de las solicitudes para alumbramiento de aguas presentadas en la isla de Gran Canaria incumplían en varios puntos con lo establecidos en la Real Instrucción de 5 de junio de 1883. Entre las irregularidades detectadas debemos señalar el incumplimiento con los plazos y a la inexistencia en las solicitudes del acta de reconocimiento del terreno elaborada por parte de un Ingeniero de Minas de donde se iban a ejecutar las obras como, era preceptivo. ¿Qué se evaluaba en esta visita? Principalmente si lo que se plasmaba en el proyecto se ajustaba a la realidad: la posibilidad de alumbramiento de aguas, sus ventajas e inconvenientes, la veracidad de las oposiciones, el plazo de comienzo y finalización de las obras. Una vez finalizada las mismas se tenía que emitir otra acta de reconocimiento con los trabajos ejecutados, sin embargo en el caso de Gran Canaria se omitía la misma, por lo que es difícil cuantificar el número de

35 Boletín oficial de la provincia de Canarias no 20, del año 1918. La Gaceta de Madrid, no 211, de 30 de julio de 1865. No es hasta el día 31 de enero de 1917, en que es designado Alfonso Fernández para realizar un estudio hidrológico en la isla de Fuerteventura, siendo acompañado por el ingeniero de Minas, residente en Santa Cruz de Tenerife, cuando se produce una iniciativa estatal en esta materia.

36 Boletín oficial de la provincia de Canarias nº 95, del año 1877. 
obras de alumbramientos de agua y sus tipologías. Esto motivó una protesta por parte del Consejo de Obras públicas ante el Gobernador con fecha 29 de abril de 1919.

\section{CONCLUSIONES}

De lo expuesto en este trabajo se pueden extraer las siguientes conclusiones. En primer lugar, el cuestionario remitido por el Estado a los ayuntamientos a través de los gobernadores entre los años 1834-1835, para conocer el estado de las aguas existentes, quiénes eran sus propietarios, tipos de explotaciones y almacenamientos, destino de las aguas e intervenciones que se podían realizar para mejorar dichos aprovechamientos, fue el único intento de defensa del agua como un bien de dominio y propiedad pública.

En segundo lugar, para favorecer el proceso de privatización de las aguas y de los espacios para conducciones y almacenamiento, el Estado se dota de un conjunto normativo confuso, sin un previo estudio hidrológico, ni análisis de los espacios públicos y privados de los distintos territorios y sin tener en cuenta su diversidad y especificidad. Esta situación de falta de planificación generó muchos conflictos entre particulares, heredades y sociedades de aguas que se dirimieron en distintas instancias: judiciales y administrativas. Esta situación agravada por la lucha mantenida entre dos cuerpos de funcionarios del Estado, los Ingenieros de Minas y los de Obras Públicas, se reflejó en el ordenamiento legal ocasionando múltiples dudas sobre qué norma utilizar, de las que se favorecieron los grandes propietarios, la burguesía agraria y comercial y las élites, que eran los que disponían de los recursos económicos necesarios para emprender estas obras mediante minas, galerías y pozos artesianos (MONTERDE, 1861). El ejemplo más evidente lo observamos en el año 1871, en la consulta realizada por el Gobernador Civil de Canarias al Ministerio sobre cómo se debían tramitar los expedientes, si por lo establecido en la Ley de Aguas de 1866, o por el Decreto de Minas. Aspecto éste que se clarificó en el año 1872, con la publicación de una Orden que disponía que para alumbrar aguas se ajustara a lo dispuesto en el Decreto, $y$, una vez en la superficie, por lo fijado en la citada Ley de Aguas (Abella, 1877).

Finalmente, en el caso específico de Gran Canaria, además de las irregularidades ya reseñadas de incumplimiento con los plazos y las ausencias de las actas de reconocimientos que debían ser remitidas al Ministerio de Fomento, hay que añadir que se vulneraron los requisitos dictados para la redacción de los proyectos que debían realizarlos Ingenieros de Minas, y, sin embargo, en Canarias lo confeccionaron Ingenieros de Montes, Militares y Ayudantes de Obras Públicas, ya que el Distrito Minero de Canarias no se crea hasta el año 1877. A pesar de ello la sobreexplotación del subsuelo en busca de aguas era ya un hecho. Una prueba de ello lo vemos en el período 1871-1878, donde se solicitaron más de dos mil doscientas pertenencias mineras por partes de particulares, heredades y sociedades de agua y que, ante la falta de personal en la Sección de Fomento, fueron tramitadas por el Subgobernador de Gran Canaria, a pesar de no tener 
competencia para ello. Junto a esto hay que indicar que en todo este proceso no se tuvo en cuenta el hecho diferencial canario y sus especificidades (clima, relieve, vegetación, geología, el hecho volcánico, etc.).

Estas son solo algunas de las graves anomalías detectadas en los expedientes que desde Canarias se remitían al Ministerio de Fomento para su tramitación. Todo esto provocó una gran conflictividad social durante este período (18001927). Tenemos constancia de ello en las Islas Canarias cuando, en el año 1924, el Ministerio de Fomento, a través de una Real Orden, ${ }^{37}$ limita los alumbramientos de aguas por parte de los particulares, debido entre otras causas, a los numerosos pleitos que acontecieron, sobre todo en el norte de Tenerife. Lo que viene a confirmar esta norma es la aniquilación del subsuelo canario a efectos hídricos. En síntesis, la captación de aguas subterráneas en Gran Canaria constituye la primera gran especulación que sufre la isla. Los orígenes de los problemas de abastecimiento a poblaciones que se ponen de manifiesto a principios del siglo $x \mathrm{x}$, producto del aumento poblacional, hay que situarlos en esta época. El agua nunca ha sido considerada como un bien público y colectivo sino como el gran negocio de unos pocos.

\section{REFERENCIAS}

Abella, F. (1877): Manual de Aguas, Expropiación y Colonias Agrícolas, Imprenta E. de la Riva, Madrid.

Aguilera KlinK, F.; Cristopher NunN, S. (1989): «Problemas en la gestión del agua subterránea: Arizona, Nuevo Méjico y Canarias», Secretariado de Publicaciones. Universidad de la Laguna, Santa Cruz de Tenerife.

Carnero Lorenzo, F.; Nuez YÁnez, J.S. (2003): «Empresa capitalista y agua en Canarias, 1896-1936. Una primera aproximación», en F.J. CAlero García y E. PARRA-LóPez (coords.), Canarias empresarial: un nuevo contexto, Confederación provincial de empresarios, Santa Cruz de Tenerife: 17-30.

CARTAÑà i Piñén, J. (2005): Agronomía e Ingenieros Agrónomos en la España del siglo XIX, Ediciones del Serbal, Barcelona.

AsCANIO y LeÓn, R. DE (1926): Gran Canaria y sus aguas subterráneas (con algo sobre Tenerife, como Apéndice), Imp. y Lib. de Suc. de M. Curbelo, La Laguna de Tenerife.

León y Castillo, Juan de

DíAz CRUZ, P.L. (2013): «El agua en Canarias: una aproximación historiográfica», Vegueta, 13: 43-64.

FELIP VIDAL, V. (1878): «Aguas Subterráneas», Revista de Obras Públicas, 12 (1): 136141.

Gay DE MONTElla, R. (1921): «Derecho Hidráulico Español», Editorial Reus, Madrid. Gil Olcina, A.; Morales Gil, A., coord.. (1992): Hitos históricos de los regadios españoles, Ministerio de Agricultura, Alimentación y Medio Abiente, Madrid.

Guimerá Peraza, M. (1957): «Algunas precisiones sobre la Ley de Heredamientos

37 La Gaceta de Madrid $\mathrm{n}^{\circ}$ 338, de 3 de diciembre de 1924, pp. 1057-1058. 
de Aguas en Canarias», Anuario de Estudios Atlánticos, 8: 61-90.

Hernández González, M. (2006): Intervenciones Políticas. Pedro José Gordillo Ramos, Ediciones Idea, Santa Cruz de Tenerife.

Hernández Ramos, J. (1954): Las Heredades de Aguas de Gran Canaria, Imprenta Sáez, Madrid.

Macau Vilar, F. (1957): «Estudios Hidrológicos de Gran Canaria», Anuario de Estudios Atlánticos, 3: 9-46.

Macías Hernández, A. (1990): "Aproximación al proceso de privatización del agua en Canarias, c. 1500-1879», en M.T. Picazo y G. Lemeunier (coord.), Agua y Modo de producción, Crítica, Barcelona: 121-149.

Madoz, P. (1986): Diccionario Geográfico, Estadístico e Histórico de Canarias, Ámbito Ediciones, Valladolid.

Martín Retortillo, S. (1990): Derecho de aguas, Civitas, Madrid.

Martín Ruiz, J.F. (1989): El Noroeste de Gran Canaria. Recursos Hídricos, Agrícolas y Población, Cabildo Insular de Gran Canaria, Las Palmas de Gran Canaria.

Millares Cantero, A. (2008): Motines Insulares. Tres Estudios, Ediciones Idea, Santa Cruz de Tenerife.

Monterde, A. (1861): «Pozo artesiano de Passy», Revista de Obras Públicas, 15 (1): 192.

Moreu Ballonga, J.L. (1996): Aguas Públicas y Aguas Privadas, Editorial Bosch, Barcelona.

Ojeda Cabrera, M.P.; Macías Hernández, A. (1989): «Acerca de la revolución burguesa y su reforma agraria. La desamortización del agua», Anuario de Estudios Atlánticos, 35: 217-260.

Palau Catalá, M. (1875): «Divisiones Hidrológicas», Revista de Obras Públicas, 20 (1): 234-238.

Pérez Zabaleta, A. (2001): «Las sociedades de aguas en España. Un nuevo instrumento para la construcción de obras públicas», en Una cita europea con la nueva cultura del agua. La directiva marco: perspectivas en España y Portugal. II Congreso Ibérico sobre la planificación y gestión de las aguas, Institución Fernando el Católico, Zaragoza: 403-412.

Pérez Marrero, L.M. (1990): «El proceso de privatización de las aguas en Canarias», Anuario de Estudios Atlánticos, 36: 429-461.

Sánchez Pinto, L. (1968): Abastecimiento de Aguas a poblaciones, Cabildo Insular de Tenerife, Santa Cruz de Tenerife.

SuÁrez Grimón, V.J. (1987): La Propiedad pública, vinculada y eclesiástica en Gran Canaria, en la crisis del Antiguo Régimen, 2 vols., Cabildo Insular de Gran Canaria, Las Palmas de Gran Canaria.

SuÁrez Grimón, V.J. (1988): «El agua como motivo de conflictividad social en Gran Canaria, siglo XVIII-XIX», en F. Morales Padrón (coord.), Actas del VIII Coloquio de Historia Canario-Americana, vol. 1, Cabildo Insular de Gran Canaria, Las Palmas de Gran Canaria: 209-230.

Suárez Grimón, V.J.; Trujillo Yánez, G.A., coords. (2006): La cultura del agua. III Jornadas de Patrimonio Cultural de Teror, Anroart Ediciones, Las Palmas de Gran Canaria. 
La tramitación y gestión de los expedientes de captación de aguas subterráneas

SuÁrez Moreno, F. (2014): Minas de Agua en Gran Canaria (1501-1950). Galerías filtrantes canarias, Cabildo Insular de Gran Canaria, Las Palmas de Gran Canaria. 